\title{
Eocene calibration of geomagnetic polarity time scale reevaluated: Evidence from the Green River Formation of Wyoming
}

\author{
Malka Machlus \\ Sidney R. Hemming \\ Paul E. Olsen \\ Department of Earth and Environmental Sciences and Lamont-Doherty Earth Observatory of \\ Columbia University, Palisades, New York 10964, USA \\ Nicholas Christie-Blick
}

\begin{abstract}
We reevaluate the Eocene geomagnetic polarity time scale on the basis of single-crystal ${ }^{40} \mathrm{Ar} /{ }^{39} \mathrm{Ar}$ ages for air-fall tuffs from the Wilkins Peak Member of the Green River Formation of Wyoming. Tuff 6 is dated as $49.1 \pm 0.2 \mathrm{Ma}$, and tuff 3 is dated as $50.4 \pm 0.3$ Ma (maximum estimate). When combined with published magnetostratigraphic constraints, these age determinations suggest that the currently accepted age of chron $\mathrm{C} 22 \mathrm{r}$ is 1.5-2.5 m.y. too old, which supports a significantly longer duration for the early Eocene, for the early Eocene climatic optimum, and the Wasatchian North American Land Mammal Age.
\end{abstract}

Keywords: Green River Formation, Eocene, Ar/Ar, lacustrine, Wasatchian-Bridgerian, early Eocene climatic optimum.

\section{INTRODUCTION}

Three radiometric tie points at $33.7,46.8$, and 55.0 Ma calibrate the Eocene part of the geomagnetic polarity time scale (GPTS). The lengths of the chrons are determined by the relative widths of ocean-floor magnetic anomalies, with their boundaries set by a spline connecting these plus six other time points for the Late Cretaceous and the rest of the Cenozoic (Cande and Kent, 1992, 1995; Berggren et al., 1995; Fig. 1A).

The two older tie points for the Eocene are known to be inaccurate, the middle Eocene tie point having the greatest uncertainty. For this tie point, Bryan and Duncan (1983) provided K-Ar ages of $46.8 \pm 0.5 \mathrm{Ma}$ and $45.8 \pm 0.5$ Ma for the same tuff. Berggren et al. (1995) cited unpublished ${ }^{40} \mathrm{Ar} /{ }^{39} \mathrm{Ar}$ dating by C.C. Swisher III and A. Montanari that supports the younger age, implying a large discrepancy for the early to middle Eocene time scale (Figs. $1 \mathrm{~A}$ and $1 \mathrm{~B})$. The $55.0 \mathrm{Ma}{ }^{40} \mathrm{Ar} /{ }^{39} \mathrm{Ar}$ tie point may be too young because it is separated from the younger dated tuff upon which the age estimate is based by an unconformity (Aubry et al., 1996).

Here we present new single-crystal ${ }^{40} \mathrm{Ar} /$ ${ }^{39} \mathrm{Ar}$ ages for two air-fall tuffs in the Green River Formation of Wyoming and show that physical and magnetostratigraphic data from this lacustrine unit can be used to reevaluate the Eocene part of the GPTS. This is a first evaluation of this time-scale discrepancy, and although we cannot recalibrate the GPTS, we suggest a range of possible modifications (Figs. 1B-1D) for the existing time scale (Fig. 1A).

\section{STRATIGRAPHIC CONTEXT}

The lower Eocene Green River Formation is well developed in the greater Green River basin (Fig. 2; Bradley, 1964; Roehler, 1992). Numerous laterally persistent layers of air-fall tuff and sedimentary cyclicity permit a highresolution physical stratigraphy (e.g., Culbertson, 1961; Bradley, 1964; Roehler, 1992). The single-crystal ${ }^{40} \mathrm{Ar} /{ }^{39} \mathrm{Ar}$ ages reported here are from tuffs 3 and 6 of Culbertson (1961; Fig. 2) from the center of the basin. Tuff 6 is located just below a basin-wide facies transition marking the beginning of maximal expansion of Lake Gosiute (Bradley, 1964; Roehler, 1992) that can be traced into the magnetic polarity sections of Clyde et al. (1997, 2001; P1 and P2 in Figs. 2 and 3; stratigraphic details are available ${ }^{1}$ ). Potential diachrony between the basin center and margin cannot be quantified with available data. However, regional stratigraphic relations (see footnote 1) indicate that tuff 6 provides a maximum estimate for the age of the transition.

\section{RADIOMETRIC DATING}

The ${ }^{40} \mathrm{Ar} /{ }^{39} \mathrm{Ar}$ dating of the two tuffs yielded the following ages: $50.4 \pm 0.3$ Ma for tuff 3 and $49.1 \pm 0.2$ Ma for tuff 6 ( $1 \sigma$ analytical precision; Table 1; analytical methods and details are available [see footnote 1]). Although these ages are close to dates reported by Smith et al. (2003) for the same tuffs, $49.96 \pm 0.04$ $(1 \sigma) \mathrm{Ma}$ and $49.70 \pm 0.05(1 \sigma) \mathrm{Ma}$, respectively, our new single-crystal ages highlight

${ }^{1}$ GSA Data Repository item 2004018, analytical methods and details of stratigraphy, Figure DR1 (cumulative age-probability curves), Table DR1 (Ar isotope data), Table DR2 (inverse isochron ages), and Table DR3 (GPTS calibration data), is available online at www.geosociety.org/pubs/ft2004.htm, or on request from editing@geosociety.org or Documents Secretary, GSA, P.O. Box 9140, Boulder, CO 80301-9140, USA. problems with the accuracy and precision inherent in these dates and multicrystal dates in general. These problems are relevant to timescale reevaluation (Fig. 1) because the age of tuff 6 is used here as a calibration point.

Ages reported here and by Smith et al. (2003) for tuff 6 are directly comparable because both are from biotites and are referenced to monitor standards calibrated against the same primary standard. The estimated age of sample 245B of tuff 6 (Table 1) is based mostly on single-crystal ages (27 of the 31 individual determinations); the remaining 4 determinations used two-crystal aliquots (see footnote 1). Smith et al. (2003) used aliquots of three crystals per age determination. Multicrystal ages exhibit a lower apparent spread compared to individual crystals, leading to an underestimated error. In addition, the presence of two or more age populations in a sample results in an offset of the weighted mean age in multicrystal data. Both effects lead to geologic uncertainty significantly greater than stated analytical uncertainty.

Individual ages of sample 245B exhibit large scatter (245B-a in Table 1; Fig. 4A) with an age distribution showing more than one age population. The age of the youngest population is preferred, assuming minimal alteration, because the biotite crystals were euhedral, radiogenic, and there is no evidence of reworked detrital grains. Each age population is selected to include the maximum number of individual ages and to minimize the mean squared weighted deviates (MSWD; see Table 1 and footnote 1) of the calculated age. By these criteria, the inferred main population (245B-b in Table 1; Fig. 4A) actually contains two components (245B-c and 245B-d in Table 1). The preferred age for tuff 6 is thus the younger (49.1 Ma; 245B-c in Table 1), although additional analyses are needed to resolve it better.

Multicrystal dating of tuff 6 by Smith et al. (2003) artificially suggests only one population, with few outliers, and much less scatter, with a 0.3 m.y. $(n=26)$ standard deviation compared to our 0.9 m.y. $(n=31$; 245B-a in Table 1; Fig. 4B). Therefore, their standard error of 0.05 m.y. $(1 \sigma)$ significantly underestimates uncertainty and mainly reflects the standard error of the neutron-flux gradient. In addition, multicrystal aliquots are liable to in- 


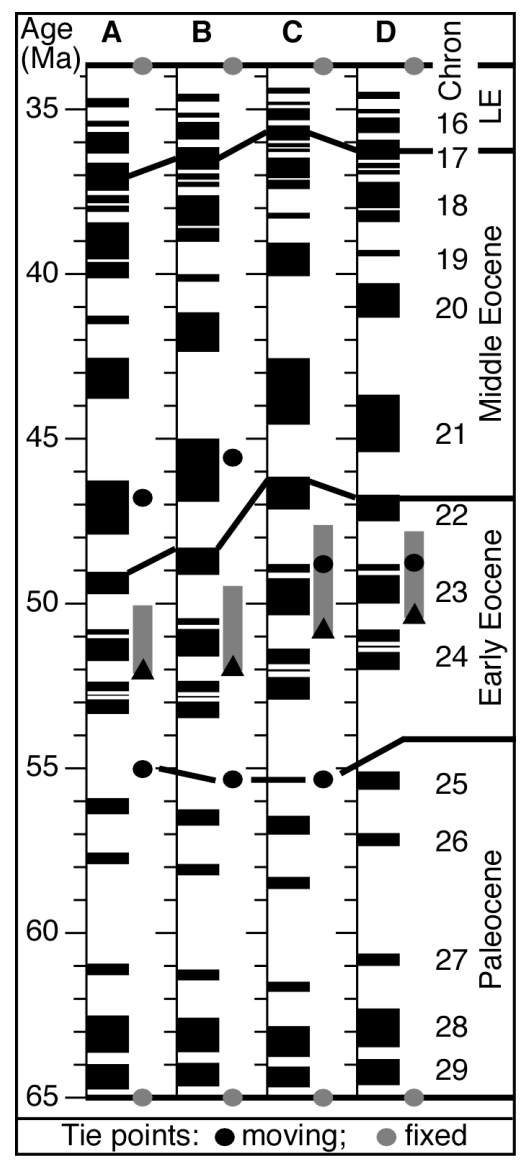

Figure 1. A: Paleocene and Eocene geomagnetic polarity time scale (Cande and Kent, 1995; using tie points 46.8 and 55.0 Ma within Eocene) and epoch boundaries (Berggren et al., 1995). B-D: Alternative versions of time scale based on following ages in place of two Eocene tie points: (B) 45.6 Ma (unpublished age; Swisher and Montanari, in Berggren et al. 1995) and $55.3 \mathrm{Ma}$ (estimated by Wing et al., 2000); (C) $48.8 \mathrm{Ma}$ (reported here) and 55.3 Ma; (D) 48.8 Ma (using one point instead of two). Alternative time scales are based on natural cubic spline passing through nine tie points, as in Cande and Kent (1992). Tie points other than two indicated are unchanged (33.7 Ma and 65.0 Ma are shown). Numerical results are available (see footnote 1). Symbols: Gray bar-early Eocene climatic optimum; triangle-Wasatchian-Bridgerian North American Land Mammal Age boundary. LE-late Eocene.

clude crystals older than the tuff layer, thereby offsetting the mean age toward an older value, perhaps explaining the $49.7 \mathrm{Ma}$ age of Smith et al. (2003), compared with our 49.1 Ma estimate (cf. B and A in Fig. 4).

Ages of individual crystals from tuff 3 are also associated with large scatter (15B-a in Table 1) and further illustrate the drawbacks of multicrystal dating. Biotite crystals from sample $15 \mathrm{~B}$ appear to cluster in two populations
(15B-b and 15B-c in Table 1; Fig. DR1A [see footnote 1]), contrasting with multicrystal analyses of the same tuff (12B in Table 1; Fig. DR1B [see footnote 1]). The multicrystal age is offset toward the older population and therefore is inaccurate. Considering the small number of measurements contributing to the younger age estimate (15B-b in Table 1) and the still younger age of $49.96 \pm 0.04(1 \sigma) \mathrm{Ma}$ reported by Smith et al. (2003), the latter is regarded as the better estimate. Nevertheless, our individual age determinations provide a first estimate of the full potential age scatter of Green River Formation tuffs that contrasts with the apparent low age scatter of multicrystal biotite ages. Similarly, the multicrystal sanidine ages of Smith et al. (2003) are based on even larger aliquots per individual age, therefore artificially eliminating any age scatter.

The large age scatter is not specific to biotite, as demonstrated by sanidine ages from ash 8 of Mono Lake, California, by Kent et al. (2002). Individual crystals yield an isochron age of $762.9 \pm 0.5 \mathrm{ka}(n=13)$, while independent bracketing data suggest $30.4 \mathrm{ka}$. One explanation for the scatter in both the Green River data and for the anomalously old age of the Mono Lake ash is the incorporation of xenocrysts during eruption. That said, the true age of Green River tuff 6 cannot be much younger than that reported here, because the multicrystal ages of seven tuffs from the Green River Formation are all in stratigraphic order (Fig. 2B), including tuffs above and below tuff 6 (Smith et al., 2003). Therefore, the incorporation of xenocrysts into those multicrystal ages should not have produced an offset of more than a few hundred thousand years.

Summarizing the pertinent data, the best age estimate for tuff 6 is $49.1 \pm 0.2 \mathrm{Ma}$, which is equivalent to $48.8 \pm 0.2 \mathrm{Ma}$ if the 27.84 Ma Fish Canyon sanidine reference age of the GPTS is used (Berggren et al., 1995). We use $48.8 \pm 0.2 \mathrm{Ma}$ as a maximum age for the correlative stratigraphic interval within the magnetic polarity sections of Clyde et al. (1997, 2001; Fig. 3) and as a tie point for reevaluation of the GPTS (Figs. 1C and 1D).

\section{CORRELATION WITH THE GPTS}

Land-mammal biostratigraphy constrains the correlation between local magnetostratigraphy and the GPTS (Clyde et al., 2001): the lowermost and uppermost normal-polarity zones of Clyde et al. (1997, 2001; L, U in Fig. $3 \mathrm{~A})$ are no older than chron C24n and no younger than chron C21n. However, this scheme does not integrate additional published radiometric ages or explain the apparent discrepancy between the correlation of Smith

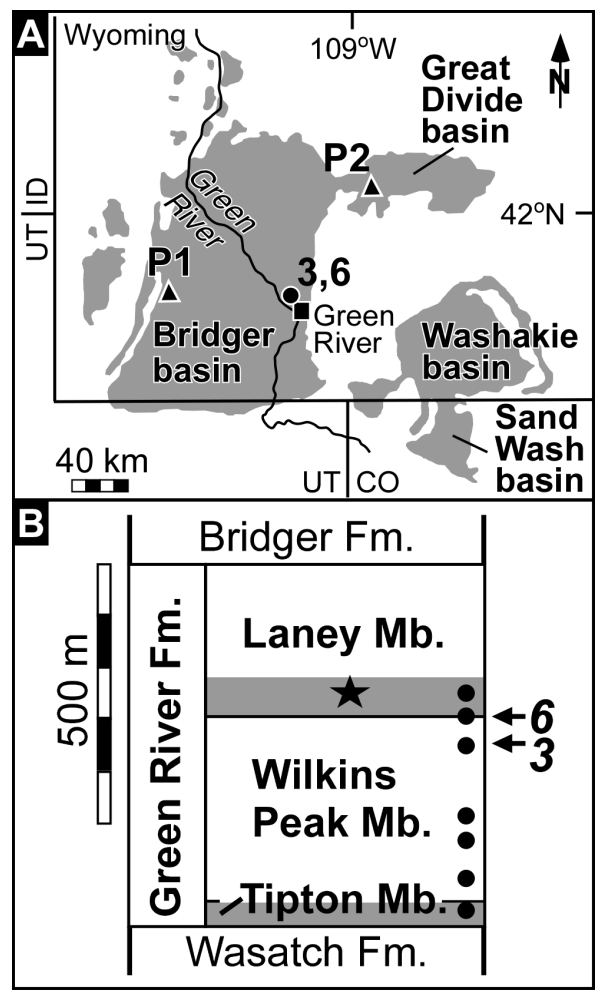

Figure 2. A: Locations of tuff sample localities (3 and 6), referenced magnetostratigraphic sections (P1 and P2) of Clyde et al. (1997, 2001), and areal extent (shaded) of Green River Formation, Wyoming (from Grande, 1984). Basins named on map constitute greater Green River basin. Coordinates of sample localities near Green River, Wyoming, are: tuff 3, Tollgate Rock, $41^{\circ} 32^{\prime} 32^{\prime \prime} \mathrm{N}, 109^{\circ} 28^{\prime} 56^{\prime \prime} \mathrm{W}$; tuff 6 , Palisades, $41^{\circ} 33^{\prime} 20^{\prime \prime} \mathrm{N}, 109^{\circ} 30^{\prime} 02^{\prime \prime} \mathrm{W}$. B: Generalized stratigraphy of Green River Formation from core near center of Bridger basin (Roehler, 1991). Shaded intervals are oil shales; star locates interval of maximum lake expansion; dots mark location of dated tuffs (Smith et al., 2003; this paper). Abbreviations: UTUtah; ID-Idaho; CO-Colorado; Mb.member; Fm-formation.

et al. (2003) with the GPTS and the local magnetic polarity pattern (e.g., cf. time scale in Fig. 3A and ages in Fig. 3B). We suggest that all the data can be reconciled by a revision of the early Eocene time scale. We use alternative ages for the tie points, including the age of tuff 6 (Figs. 1C and 1D), to constrain the possible change to the Eocene time scale.

The lowermost polarity zone of Clyde et al. (1997, 2001; L in section P1, Fig. 3A) contains a fauna of late Wasatchian North American Land Mammal Age (NALMA) (Zonneveld et al., 2000). The age of the early Wasatchian is well constrained in the Bighorn basin, Wyoming, by a fauna younger than the Paleocene-Eocene boundary (Wing, 1984) and found in a reverse-polarity interval (Clyde et al., 1994; Tauxe et al., 1994) correlated with chron C24r (Berggren et al., 1995). The inter- 
Figure 3. A: Comparison of magnetostratigraphy for sections P1 and P2 (from Clyde et al., 1997, 2001) with geomagnetic polarity time scale (GPTS). See Figure 2 for locations. Wasatchian and Bridgerian refer to land mammal ages. Abbreviations: $\mathrm{Br}-$ Bridger Formation; Wa-Wasatch Formation. Members of Green River Formation: Ln-Laney Member; WP-Wilkins Peak Member; T-Tipton Member. B: ${ }^{40} \mathrm{Ar} /{ }^{39} \mathrm{Ar}$ ages of tuffs (tuff 6, this paper; Rife tuff, from Smith et al.,

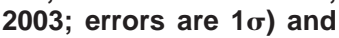
their stratigraphic locations, eastern Green River basin (GRB). Ages are

referenced to Fish Canyon sanidine age of $27.84 \mathrm{Ma}$, for direct comparison to GPTS. Note discrepancy between ages in B and GPTS time scale in A, when using correlation scheme of Clyde et al. (2001). val of normal polarity at the base of section $\mathrm{P} 1$ is thus inferred to be equivalent to or younger than chron C24n (Fig. 3A).

The uppermost polarity zone of Clyde et al. (1997, 2001) contains mammal fossils of early Bridgerian NALMA (U in section P2, Fig. $3 \mathrm{~A})$. Younger, late Bridgerian faunas of southern California predate planktonic foraminiferal zone P10 and nannofossil zones CP12bCP13b (Flynn, 1986; Walsh et al., 1996), which are together correlated with chrons C21r, C21n, and C20r (Berggren et al., 1995). The interval of normal polarity at the top of section P2 is therefore inferred to be equivalent to or older than chron C21n (Fig. 3A).

Clyde et al. (2001) correlated a sequence of normal-reverse-normal polarity immediately below the Laney Member in both sections (M1 and M2 in Fig. 3A) with a similar se-

quence within chron $\mathrm{C} 23 \mathrm{n}$. The age of the facies change at the base of the Laney Member is bracketed by the beginning and end of chron C22r (50.8-49.7 Ma; Berggren et al., 1995; Fig. 3A). Because this facies change is near the base of the interval of reverse polarity and likely closer to the older date, the age reported here for tuff 6 (245B-c in Table 1) suggests that the same horizon is younger than 48.8 Ma (Fig. 3B), a discrepancy of as much as 2 m.y. with respect to the GPTS.

To resolve the age conflict, Smith et al. (2003) correlated the interval of mostly normal polarity beneath tuff 6 (M1 and M2 in Fig. 3A) with chron C22n, despite the discrepant magnetic polarity patterns. The persistence of this pattern at the same stratigraphic level (upper Wasatch Formation; lower Bridgerian NALMA; M1 and M2 in Fig. 3A) in

TABLE 1. ${ }^{40} \mathrm{Ar} /{ }^{39} \mathrm{Ar}$ AGE SUMMARY

\begin{tabular}{|c|c|c|c|c|c|c|c|c|}
\hline Sample* & Method $(N)^{\dagger}$ & Age (Ma) & $\pm 1 \sigma^{\S}$ & $\pm 1 \sigma^{\#}$ & $\mathrm{SD}^{* *}$ & ${ }^{40} \mathrm{Ar} /{ }^{36} \mathrm{Ar}$ & $\pm 1 \sigma$ & MSWD \\
\hline \multicolumn{9}{|l|}{ Tuff 3: } \\
\hline$\overline{15 B-a}$ & I (21) & 50.10 & 0.20 & 0.50 & 2.7 & 292 & 2 & 37.2 \\
\hline 15B-b & I (7) & 50.37 & 0.25 & 0.52 & 0.3 & 290 & 7 & 1.7 \\
\hline 15B-C & I (6) & 51.75 & 0.30 & 0.56 & 0.4 & 296 & 4 & 1.2 \\
\hline $12 B$ & I (19) & 50.78 & 0.34 & 0.57 & 1.3 & 291 & 6 & 1.3 \\
\hline \multicolumn{9}{|l|}{ Tuff 6: } \\
\hline$\overline{245 B-a}$ & WM (31) & 49.33 & 0.18 & 0.48 & 0.9 & $\mathrm{NA}^{+\dagger}$ & NA & 2.5 \\
\hline 245B-b & WM (19) & 49.28 & 0.18 & 0.48 & 0.3 & NA & NA & 1.2 \\
\hline 245B-C & WM (11) & 49.12 & 0.18 & 0.48 & 0.2 & NA & NA & 0.6 \\
\hline 245B-d & WM (8) & 49.69 & 0.19 & 0.49 & 0.1 & NA & NA & 0.5 \\
\hline
\end{tabular}

Note: Single-step laser-fusion data were collected in the Ar geochronology laboratory at Lamont-Doherty Earth Observatory (for details, see footnote 1 in text). Ages and errors are computed as in Renne et al. (1998) and reported relative to the Fish Canyon sanidine age of $28.02 \mathrm{Ma}$. Preferred age is in bold; see text for explanation. $J$ values: $2.3113 \times 10^{-03} \pm 8.23 \times 10^{-06}(N=11$; samples $15 \mathrm{~B}, 245 \mathrm{~B}), 8.6123 \times 10^{-04} \pm 4.86 \times 10^{-06}(N=$ 4; sample 12B).

* Minerals: B-biotites; a-d-see text for explanation.

† WM-weighted mean; 1 -inverse isochron; $N=$ number of individual age determinations.

$\S$ Analytical error.

\# Full external errors.

** SD—standard deviation.

t† NA-not applicable.

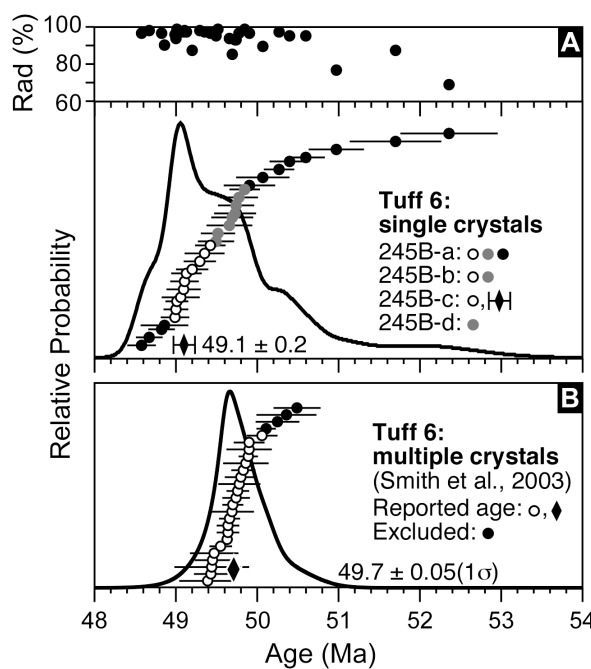

Figure 4. Comparison between (A) singlecrystal and (B) multicrystal (from Smith et al., 2003) ${ }^{40} \mathrm{Ar} /{ }^{39} \mathrm{Ar}$ dating of tuff 6 . Each circle represents one age determination. Thick lines are cumulative probability curves. Percentage of radiogenic Ar shown in A is for age reported here. Open, shaded, and black circles mark groups of age determinations interpreted as different age populations (see data in Table 1 for populations 245B-a-245Bd designated in $A$; details are available [see footnote 1]). Diamonds mark age estimate for each sample. Errors are $1 \sigma$.

sections $170 \mathrm{~km}$ apart (P1 and $\mathrm{P} 2$ in Fig. 2A) favors correlation with an interval associated with the same pattern in the GPTS (Clyde et al., 2001).

Another age conflict exists at the stratigraphic level of the Tipton Member in the Clyde et al. (1997) section (P1 in Fig. 3A). The lowermost age of Smith et al. (2003) dates this member as $50.92 \pm 0.15(1 \sigma) \mathrm{Ma}$ (relative to a Fish Canyon sanidine age of 27.84 Ma). The Clyde et al. (2001) correlation to the GPTS dates the correlative interval as $52.3 \mathrm{Ma}, 1.4$ m.y. older. Smith et al. (2003) suggested that this interval contains an unrecorded normal-polarity magnetic zone and correlated the Tipton Member to chron C23n (ca. $51 \mathrm{Ma}$; Fig. 3A), but the age conflict can be resolved without recourse to a phantom polarity zone, if the GPTS is modified (Figs. 1C and 1D).

Our data suggest that the base of chron $\mathrm{C} 22 \mathrm{r}$ should be revised to be $2 \mathrm{~m}$.y. younger at $48.8 \mathrm{Ma}$, with a probable range of 1.5-2.5 m.y. (considering the age scatter of individual crystal ages for tuff 6). An exact calibration of the GPTS is not possible, however, because our age is a maximum. Instead, three calibration schemes for the Eocene and Paleocene GPTS are considered as alternative approximations (Figs. 1B-1D), on the basis of different ages for the problematic calibration points of 46.8 Ma and 55 Ma (Cande and Kent, 
1995; Fig. 1A). We favor the time scale in Figure 1C.

These approximate calibration schemes for the GPTS (Figs. 1B-1D) can be assessed by the implied spreading rate. Jumps in this record are very unlikely, and thus a minimum number of calibration points should be used (Cande and Kent, 1992). Too few calibration points, however, underestimate the spreading rate change, and therefore we do not favor the calibration scheme with only one calibration point (Fig. 1D).

Lack of better information regarding the $\mathrm{Pa}$ leocene-Eocene (P-E) 55 Ma tie point leads us to use the 55.3 Ma estimate of Wing et al. (2000). It is based on magnetostratigraphy in the Bighorn basin (Tauxe et al., 1994), biostratigraphy (P-E boundary identified by Wing, 1984), and a ${ }^{40} \mathrm{Ar} /{ }^{39} \mathrm{Ar}$ age of $52.8 \pm$ $0.16 \mathrm{Ma}$ (Wing et al., 1991) correlated to the base of chron C24n.1n (Tauxe et al., 1994). Although this radiometric age is from an age spectrum of a bulk sample, any potential inaccuracy is small, compared with the uncertainty associated with the middle Eocene tie point. We favor this calibration scheme (Fig. 1C) because it best incorporates all radiometric and magnetostratigraphic constraints from the Green River and the Bighorn basins. Note, however, that this calibration scheme is still not ideal because the reported age is close to the 55.3 Ma tie point, and it may imply a jump in spreading rate. Our fourth calibration scheme (Fig. 1B) uses both the Wing et al. (2000) estimate for the P-E tie point and an unpublished 45.6 $\mathrm{Ma}{ }^{40} \mathrm{Ar} /{ }^{39} \mathrm{Ar}$ age (C.C. Swisher III and A. Montanari, in Berggren et al., 1995) for the same ash that yielded the 46.8 Ma K/Ar calibration age used by Cande and Kent (1995). This scheme does not fully meet the constraints from the Green River basin and is probably a minimum estimate of the required time-scale revision.

Two important implications are apparent in all three calibrations (Figs. 1B-1D). The first is lengthening of the early Eocene by $0.7-2.5$ m.y., with the maximum change within the early-middle Eocene. The second is a near doubling (0.5-1.5 m.y. increase) of the early Eocene climatic optimum, a warm interval of time between 52 and 50 Ma (Zachos et al., 2001). In addition, the Wasatchian-Bridgerian NALMA boundary, within chron C23r (Clyde et al., 1997, 2001; Zonneveld et al., 2000), is $\sim 1 \mathrm{~m}$.y. younger at $51 \mathrm{Ma}$ (Figs. 1C and 1D), affecting terrestrial records dated by this biostratigraphy.

Further implications are for interpreting cyclic records of the early and middle Eocene. The Green River Formation in particular is considered a classic example of orbitally forced record. Pietras et al. (2003) suggested that the observed cyclicity cannot be forced by precession. However, allowing for larger scatter and age bias as presented here, the observed cyclicity can very well be orbitally forced.

\section{ACKNOWLEDGMENTS}

This research was supported by National Science Foundation grant ATM 00-82402 (to Olsen, ChristieBlick, and Hemming), by a David Love Field Geology Fellowship and a Colorado Scientific Society Oriel Memorial Fund research grant (to Machlus), by the Lamont Climate Center, and by the Department of Earth and Environmental Sciences at Columbia University. We thank W.C. Clyde and an anonymous reader for reviews, and M.A. Hoffmann for access to the Palisades outcrop (Wyoming). Lamont-Doherty Earth Observatory contribution 6531 .

\section{REFERENCES CITED}

Aubry, M.P., Berggren, W.A., Stott, L., and Sinha, A., 1996, The upper Paleocene-lower Eocene stratigraphic record and the Paleocene-Eocene boundary carbon isotope excursion: Implications for geochronology, in Dunay, R.E., ed., Correlation of the early Paleogene in northwest Europe: Geological Society [London] Special Publication 101, p. 353-380.

Berggren, W.A., Kent, D.V., Swisher, C.C., III, and Aubry, M.P., 1995, A revised Cenozoic geochronology and chronostratigraphy, in Berggren, W.A., et al., eds., Geochronology, time scales and global stratigraphic correlation: SEPM (Society for Sedimentary Geology) Special Publication 54, p. 129-212.

Bradley, W.H., 1964, Geology of Green River Formation and associated Eocene rocks in southwestern Wyoming and adjacent parts of Colorado and Utah: U.S. Geological Survey Professional Paper 496-A, p. A1-A86.

Bryan, W.B., and Duncan, R.A., 1983, Age and provenance of clastic horizons from Hole 516F, in Barker, P.F., Carlson, R.L., Johnson, D.A., et al., Initial reports of the Deep Sea Drilling Project, Volume 72: Washington, D.C., U.S. Government Printing Office, p. 475-477.

Cande, S.C., and Kent, D.V., 1992, A new geomagnetic polarity time scale for the Late Cretaceous and Cenozoic: Journal of Geophysical Research, v. 97 , p. $13,917-13,951$.

Cande, S.C., and Kent, D.V., 1995, Revised calibration of the geomagnetic polarity timescale for the Late Cretaceous and Cenozoic: Journal of Geophysical Research, v. 100, p. 6093-6095.

Clyde, W.C., Stamatakos, J., and Gingerich, P.D., 1994, Chronology of the Wasatchian land-mammal age (early Eocene): Magnetostratigraphic results from the McCullough Peaks section, northern Bighorn Basin, Wyoming: Journal of Geology, v. 102, p. $367-377$.

Clyde, W.C., Zonneveld, J.P., Stamatakos, J., Gunnell, G.F., and Bartels, W.S., 1997, Magnetostratigraphy across the Wasatchian/Bridgerian NALMA boundary (early to middle Eocene) in the western Green River basin, Wyoming: Journal of Geology, v. 105 , p. 657-669.

Clyde, W.C., Sheldon, N.D., Koch, P.L., Gunnell, G.F,, and Bartels, W.S., 2001, Linking the Wasatchian/ Bridgerian boundary to the Cenozoic global climate optimum: New magnetostratigraphic and isotopic results from South Pass, Wyoming: Palaeogeography, Palaeoclimatology, Palaeoecology, v. 167 , p. $175-199$

Culbertson, W.C., 1961, Stratigraphy of the Wilkins Peak Member of the Green River Formation, Firehole Basin Quadrangle, Wyoming, Article
348: U.S. Geological Survey Professional Paper 424-D, p. D170-D173.

Flynn, J.J., 1986, Correlation and geochronology of middle Eocene strata from the western United States: Palaeogeography, Palaeoclimatology, Palaeoecology, v. 55, p. 335-406.

Grande, L., 1984, Paleontology of the Green River Formation, with a review of the fish fauna (second edition): Geological Survey of Wyoming Bulletin $63,333 \mathrm{p}$.

Kent, D.V., Hemming, S.R., and Turrin, B.D., 2002, Laschamp excursion at Mono Lake?: Earth and Planetary Science Letters, v. 197, p. 151-164.

Pietras, J.T., Carroll, A.R., Singer, B.S., and Smith, M.E., 2003, 10 k.y. depositional cyclicity in the early Eocene: Stratigraphic and ${ }^{40} \mathrm{Ar} /{ }^{39} \mathrm{Ar}$ evidence from the lacustrine Green River Formation: Geology, v. 31, p. 593-596.

Renne, P.R., Swisher, C.C., Deino, A.L., Karner, D.B. Owens, T.L., and DePaolo, D.J., 1998, Intercalibration of standards, absolute ages and uncertainties in ${ }^{40} \mathrm{Ar} /{ }^{39} \mathrm{Ar}$ dating: Chemical Geology, v. 145 , p. $117-152$.

Roehler, H.W., 1991, Chart showing identification of oil shale and trona beds and their geophysical log responses in the Union Pacific Railroad Company El Paso corehole no. 44-3, Eocene Green River Formation, southwest Wyoming: U.S. Geological Survey Miscellaneous Field Studies Map MF-2188, 1 sheet.

Roehler, H.W., 1992, Correlation, composition, areal distribution, and thickness of Eocene stratigraphic units, greater Green River basin, Wyoming, Utah, and Colorado: U.S. Geological Survey Professional Paper 1506-E, p. E1-E49.

Smith, M.E., Singer, B., and Carroll, A.R., $2003,{ }^{40} \mathrm{Ar} /$ ${ }^{39} \mathrm{Ar}$ geochronology of the Eocene Green River Formation, Wyoming: Geological Society of America Bulletin, v. 115, p. 549-565.

Tauxe, L., Gee, J., Gallet, Y., Pick, T., and Bown, T. 1994, Magnetostratigraphy of the Willwood Formation, Bighorn Basin, Wyoming: New constraints on the location of Paleocene/Eocene boundary: Earth and Planetary Science Letters, v. 125 , p. $159-172$.

Walsh, S.L., Prothero, D.R., and Lundquist, D.J., 1996 Stratigraphy and paleomagnetism of the middle Eocene Friars Formation and Poway Group, southwestern San Diego County, California, in Prothero, D.R., and Emry, R.J., eds., The terrestrial Eocene-Oligocene transition in North America: Cambridge, Cambridge University Press, p. $120-154$

Wing, S.L., 1984, A new basis for recognizing the Paleocene/Eocene boundary in Western Interio North America: Science, v. 226, p. 439-441.

Wing, S.L., Brown, T.M., and Obradovich, J.D., 1991, Early Eocene biotic and climatic change in interior western North America: Geology, v. 19, p. 1189-1192.

Wing, S.L., Bao, H., and Koch, P.L., 2000, An early Eocene cool period? Evidence for continental cooling during the warmest part of the Cenozoic, in Huber, B.T., et al., eds., Warm climates in Earth history: Cambridge, Cambridge University Press, p. 197-237.

Zachos, J., Pagani, M., Sloan, L., Thomas, E., and Billups, K., 2001, Trends, rhythms, and aberrations in global climate $65 \mathrm{Ma}$ to present: Science, v. 292 , p. $686-693$.

Zonneveld, J.P., Gunnell, G.F., and Bartels, W.S., 2000 Early Eocene fossil vertebrates from the southwestern Green River basin, Lincoln and Uinta Counties, Wyoming: Journal of Vertebrate Paleontology, v. 20, p. 369-386.

Manuscript received 4 August 2003

Revised manuscript received 17 October 2003

Manuscript accepted 21 October 2003

Printed in USA 